\title{
Descriptive epidemiology of salivary gland neoplasms in Nigeria: An AOPRC multicenter tertiary hospital study
}

\section{Olufemi Gbenga Omitola $^{1}$ | Olujide Oladele Soyele ${ }^{2}$ | Azeez Butali ${ }^{3}$ |}

Abdulwarith Olaitan Akinshipo $^{4}$ | Dickson Okoh ${ }^{5}$ | Opeyemi Sigbeku ${ }^{6}$ |

Olajumoke Ajibola Effiom $^{4}$ | Kehinde Emmanuel Adebiyi ${ }^{7}$ | Adeola Mofoluwake Ladeji $^{7}$ |

Akinyele Olumuyiwa Adisa $^{6}$ | Ahmed Oluwatoyin Lawal ${ }^{6}$ | Osareniye Osayande ${ }^{8}$ |

Ramat Oyebunmi Braimah ${ }^{9}$ | Henry Ademola Adeola ${ }^{10,11}$

\footnotetext{
${ }^{1}$ Department of Oral Pathology and Biology, University of Port Harcourt, Port Harcourt, Nigeria

${ }^{2}$ Department of Oral Maxillo-facial Surgery and Oral Pathology, Obafemi Awolowo University, Ile-Ife, Nigeria

${ }^{3}$ Department of Oral Pathology, Radiology and Medicine, University of lowa, lowa City, lowa

${ }^{4}$ Department of Oral and Maxillofacial Pathology and Biology, College of Medicine, University of Lagos, Lagos, Nigeria

${ }^{5}$ Department of Oral Pathology, Federal Medical Centre, Asaba, Delta State, Nigeria

${ }^{6}$ Department of Oral Pathology, College of Medicine, University of Ibadan, Ibadan, Nigeria

${ }^{7}$ Department of Oral Pathology and Oral Medicine, Faculty of Dentistry, Lagos State University College of Medicine, Ikeja, Lagos, Nigeria

${ }^{8}$ Department of Oral Pathology and Medicine, University of Benin Teaching Hospital, Benin City, Edo, Nigeria

${ }^{9}$ Department of Dental and Maxillofacial Surgery, Usmanu Danfodiyo University Teaching Hospital, Sokoto, Nigeria

${ }^{10}$ Department of Oral and Maxillofacial Pathology, Faculty of Dentistry, University of the Western Cape and Tygerberg Hospital, Cape Town, South Africa

${ }^{11}$ Division of Dermatology, Department of Medicine, Faculty of Health Sciences and Groote Schuur Hospital, University of Cape Town, Cape Town, South Africa
}

\section{Correspondence}

Henry A. Adeola, Department of Oral and Maxillofacial Pathology, Faculty of Dentistry, University of the Western Cape and Tygerberg Hospital, Cape Town, South Africa.

Email: henry.adeola@uct.ac.za

\section{Abstract}

Objectives: Accurate diagnosis of salivary gland neoplasms (SGN) in many centers in Africa is limited by poor diagnostic resources and ancillary services. Hence, we have carried out a multicenter epidemiological study to understand the true burden of SGN in Nigeria.

Method: In this descriptive cross-sectional study, we have deployed resources available to members of the African Oral Pathology Consortium (AOPRC) to examine the burden of salivary gland lesions in Nigeria, using a multicenter approach. Data from seven major tertiary health institutions in northern, western, and southern Nigeria were generated using a standardized data extraction format and analyzed using the Epi-info software (Version 7.0, Atlanta, USA).

Result: Of the 497 cases examined across the seven centers, we observed that SGN occurred more in females than males. Overall, pleomorphic salivary adenoma (PA) was found to be the most common. PA was found to be the commonest benign SGN while adenocystic carcinoma (ADCC) was the commonest malignant SGN. Regional variations were observed for age group, diagnosis, and gender distribution. Significant 
statistical differences were found between males and females for malignant SGNs ( $p$-value $=0.037)$.

Conclusion: We found regional variation in the pattern of distribution of SGN in Nigeria. This is the largest multicenter study of SGN in Nigeria, and our findings are robust and representative of the epidemiology of this neoplasm in Nigeria.

KEYWORDS

AOPRC, multicenter study, Nigeria, oral pathology, Salivary gland neoplasm

\section{1 | INTRODUCTION}

Salivary gland neoplasms (SGN) are tumors that form within the tissues of major or minor salivary glands. SGN are an uncommon heterogeneous group of lesions, with varying biological features, arising within tissue of the major or minor salivary glands (El-Naggar, Chan, Grandis, Takata, \& Slootweg, 2017). There is a dearth of information on the total incidence of SGN in various regions due to underreporting of cases in national cancer registries (Valstar et al., 2017).

The global annual incidence of SGN is $0.4-13.5$ cases per 100,000 individuals and has a prevalence of $3 \%-6 \%$ of all head and neck tumors depending on the study (Tian, Li, Wang, Hu, \& Li, 2010).

There are up to 35 different lesions categorized by WHO as SGN with vast majority (ca. 65\%-75\%) of them designated as benign neoplasm (El-Naggar et al., 2017; Mehanna, McQueen, Robinson, \& Paleri, 2012). Salivary gland carcinoma (SGC), although less common, represents at least 24 different histological subtypes, making it a challenging group of lesions to study and develop treatment standards for (Leivo, 2006).

Most publications have indicated a slight female predominance; however, the sex ratio varies in different tumor types (de Oliveira et al., 2009; Li, Li, Wen, Liu, \& Zhao, 2008).

No racial differences have been clearly defined; however, Yaor (2010) reported different patterns of salivary gland tumors between Africa and the western regions of the World.

There is a wide age distribution, with a peak incidence in the fifth decade (Barnes, 2009).

The etiology of SGN is largely unknown (Boukheris, Curtis, Land, \& Dores, 2009). Unlike oral cancers, which are largely associated with tobacco usage and alcohol consumption, studies have shown that there is no independent effect of smoking and drinking on the risk of SGC (Li et al., 2017). Exposure to ionizing radiation is associated with an increased risk of SGN (El-Naggar et al., 2017; Preston-Martin \& White, 1990). SGCs have been found more associated with alterations of the immune status as found in HIV/AIDS infection (Ebrahim, Singh, \& Ramklass, 2014) and Sjogren's syndrome (Fragkioudaki, Mavragani, \& Moutsopoulos, 2016). Also, the role of genetic and viral etiology is yet to be fully investigated (Yin \& $\mathrm{Ha}$, 2016).

Tumors can occur in both the major and the minor salivary glands, and most series published in the literature showed that SGC is commoner in major salivary glands, especially the parotid (20\%$25 \%$ ) (Arshad, 1998). This rises to $40 \%$ for the submandibular glands, and more than $90 \%$ of sublingual gland tumors are malignant and almost always carcinomas (Arshad, 1998; Loyola, Araujo, Sousa, \& Araujo, 1995). When they affect minor salivary glands, the palate is the most affected site (Speight \& Barrett, 2002). Although discrepancies exist in the literature with regard to the commonest SGC, most studies have shown mucoepidermoid carcinoma, adenoid cystic carcinoma, and carcinoma ex pleomorphic adenoma as the commonest histologic types (Eveson \& Cawson, 1985; Lima, Soares, Amorim, \& Freitas Rde, 2005; Ribeiro Kde, Kowalski, Saba, \& Camargo, 2002).

Salivary gland tumors typically present as long-standing or recently developing lump in the affected gland and may lead to xerostomia as a result of blockage of the salivary duct. In the early stages, it is often difficult to clinically delineate benign from malignant lesions. However, signs such as facial nerve damage/palsy, pain, and paresthesia are commoner in malignant salivary gland lesions; so is fixation or tethering of the swelling to the overlying skin, induration, and ulceration of the mucosa (Mehanna et al., 2012).

Albeit sometimes inconclusive, diagnostic techniques such as fine needle aspiration cytology (FNAC) have been used for SGCs (Thoeny, 2007). FNAC can be subject to sampling bias, particularly if the tumor is in the deep lobe of the parotid (Thoeny, 2007). Not least, some authors have reported cases of tumor capsule seeding following FNAC procedures (Freling, Crippa, \& Maroldi, 2016; Haldar, Sinnott, Tekeli, Turner, \& Howlett, 2016; Sood, McGurk, \& Vaz, 2016). Other diagnostic imaging techniques such as magnetic resonance imaging (MRI), computed tomography (CT), and ultrasonography (US) have been found highly beneficial in the diagnosis of SGC tumor location, extent, and the presence of perineural invasion (Haldar et al., 2016; Rudack, Jörg, Kloska, Stoll, \& Thiede, 2007). Although revision of the current preoperative diagnostic approaches is deemed necessary, as neither CT, US nor MRI was found to be superior in the diagnostic work-up of SGCs (Rudack et al., 2007).

The histogenesis of SGC may be from acinar cell, stem cells, or reserve cells in the duct system (Chaudhry et al., 1989). This histologic diversity is further complicated by the presence of extracellular matrix component which is believed to be secreted by myoepithelial cells (Marx \& Stern, 2003). It is more likely that there is involvement of one cell type in SGC histogenesis (Leivo, 2006). 
TAB LE 1 Distribution of tumor by age groups

\begin{tabular}{|lccc|}
\hline $\begin{array}{l}\text { Age group } \\
\text { (years) }\end{array}$ & Benign (\%) & Malignant (\%) & Total (\%) \\
\hline$<10$ & $5(2.6 \%)$ & $4(1.3 \%)$ & $9(1.8 \%)$ \\
\hline 10 to 19 & $19(10.1 \%)$ & $11(3.6 \%)$ & $30(6.0 \%)$ \\
\hline 20 to 29 & $40(21.2 \%)$ & $28(9.1 \%)$ & $68(13.7 \%)$ \\
\hline 30 to 39 & $44(23.2 \%)$ & $59(19.2 \%)$ & $103(20.7 \%)$ \\
\hline 40 to 49 & $39(20.6 \%)$ & $64(20.8 \%)$ & $103(20.7 \%)$ \\
\hline 50 to 59 & $24(12.7 \%)$ & $53(17.2 \%)$ & $77(15.5 \%)$ \\
\hline 60 to 69 & $14(7.4 \%)$ & $51(16.6 \%)$ & $65(13.1 \%)$ \\
\hline 70 to 79 & $2(1.1 \%)$ & $25(8.1 \%)$ & $27(5.4 \%)$ \\
\hline$>80$ & $2(1.1 \%)$ & $13(4.2 \%)$ & $15(3.0 \%)$ \\
\hline Total & $189(100.0)$ & $308(100.0 \%)$ & $497(100.0 \%)$ \\
\hline
\end{tabular}

Consensus is that, the global prevalence of SGN is not well established (Pinkston \& Cole, 1999), and there is a need for more qualitative data to establish its pattern in various regions of the world. Even though several papers have been published on salivary gland tumors in sub-Saharan Africa (particularly from Nigeria) (Fomete, Adebayo, \& Ononiwu, 2015; Ladeinde, Adeyemo, Ogunlewe, Ajayi, \& Omitola, 2007; Otoh, Johnson, Olasoji, Danfillo, \& Adeleke, 2005), most are culled from single institutions. One important limitation of single center studies, inter alia, is the fact that it obscures the complete picture of the disease entity being investigated since data obtained are not representative of the entire population. In order to understand the clinical features and design novel treatment modalities that improve both diagnostic and treatment outcomes, it is necessary to evaluate the pattern and distribution of these heterogeneous tumors. This study was a collaboration of data accessed from seven different tertiary medical institutions across northern and southern Nigeria,involving members of the African Oral Pathology Research Consortium (AOPRC). A multicenter study of this caliber allowed us to investigate regional variations in SGN among people from the most populous nation in Africa.

\section{2 | MATERIALS AND METHODS}

\section{1 | AOPRC participants}

The African Oral Pathology Research Consortium (AOPRC) was inaugurated during the 1 st regional congress of the International Association of Oral Pathologists (IAOP), which took place in Lagos, Nigeria in September 2015. The objectives for creating AOPRC include the following: advancing multicenter collaborative oral pathology research; exchange of skills and expertise; and strengthening ties between oral pathologists across Africa and further afield, inter alia. The AOPRC currently has members based at the University of Ibadan, Nigeria; University of Port Harcourt, Nigeria; University of Lagos, Nigeria; Obafemi Awolowo University, Ile-Ife, Nigeria; Federal Medical Centre, Asaba, Nigeria; University of Cape Town,
South Africa; University of the Western Cape at Tygerberg Hospital, South Africa; and University of lowa, USA. A multicenter study on the burden of salivary gland tumors in Nigeria was carried out due to the collaborative efforts of the AOPRC.

\section{2 | Data source}

Deidentified secondary archived data from seven major tertiary health institutions in southwest, northwest, and south-south regions of Nigeria were used in this study. Records of all patients with salivary glands tumors (benign and malignant) at the Lagos University Teaching Hospital (LUTH), Lagos State University Teaching Hospital (LASUTH), University College Hospital, Ibadan (UCH), Obafemi Awolowo University Teaching Hospital, lle-Ife (OAUTHC) all in South-West Nigeria; University of Port Harcourt Teaching Hospital (UPTH), University of Benin Teaching Hospital (UBTH) both in South-South Nigeria; and Usmanu Danfodiyo University Teaching Hospital, Sokoto (UDUTH) which is in northwest Nigeria were extracted from 2007 to 2016 (10 years), using a standardized data extraction form. Demographic, clinical, and histopathological data, such as age distribution, site, gender distribution, and histological diagnosis, inter alia, were extracted from the records.

\section{3 $\mid$ Case selection and exclusion criteria}

Cases with inadequate clinical and histopathological information were excluded from the study. A total of 497 cases of salivary gland tumors were included from the participating centers. The SGN were categorized by histological type, site of primary tumor, age, and gender distribution.

TAB LE 2 Distribution of tumor diagnosis by gender

\begin{tabular}{|lcc}
\hline Diagnosis & Male (\%) & Female (\%) \\
\hline ADCC & $55(28.6 \%)$ & $87(28.6 \%)$ \\
\hline BCA & $12(6.3 \%)$ & $7(2.3 \%)$ \\
\hline CA-EX PA & $12(6.3 \%)$ & $9(3.0 \%)$ \\
\hline Malignant myoepithelioma & $3(1.6 \%)$ & $4(1.3 \%)$ \\
\hline MEC & $42(21.9 \%)$ & $46(15.1 \%)$ \\
\hline Mucinous CA & $1(0.5 \%)$ & $1(0.3 \%)$ \\
\hline Oncocytoma & $0(0.0 \%)$ & $1(0.3 \%)$ \\
\hline PA & $36(18.8 \%)$ & $128(42.0 \%)$ \\
\hline PCAC & $2(1.0 \%)$ & $2(1.0 \%)$ \\
\hline PLGA & $26(13.5 \%)$ & $16(13.5 \%)$ \\
\hline SDC & $3(1.6 \%)$ & $3(1.6 \%)$ \\
\hline WT & $0(0.0 \%)$ & $1(0.0 \%)$ \\
\hline Total & $192(100.0 \%)$ & $305(100.0 \%)$ \\
\hline
\end{tabular}

Note. ADCC, Adenoid cystic carcinoma; BCA, Basal cell adenoma; CAexPA, carcinoma ex pleomorphic adenoma; MEC, Mucoepidermoid carcinoma; PA, Pleomorphic adenoma; PCAC, Papillary Cystadenocarcinoma; PLGA, Polymorphous low-grade adenocarcinoma; SDC, Salivary ductal carcinoma; WT, Warthin tumor. 
TAB LE 3 Distribution of salivary gland neoplasm by site

\begin{tabular}{|c|c|c|c|c|c|c|c|}
\hline \multirow[b]{2}{*}{ Site } & \multicolumn{2}{|l|}{ Malignant } & \multicolumn{2}{|l|}{ Benign } & \multicolumn{2}{|l|}{ Total } & \multirow{2}{*}{$\begin{array}{l}\text { Chi-squared test } \\
\text { (p-value) }\end{array}$} \\
\hline & Frequency & Percent & Frequency & Percent & Frequency & Percent & \\
\hline \multicolumn{8}{|l|}{ Major } \\
\hline Parotid & 43 & $13.96 \%$ & 38 & $20.11 \%$ & 81 & $16 \%$ & $3.24(0.0717)^{* *}$ \\
\hline Submandibular & 21 & $6.82 \%$ & 23 & $12.17 \%$ & 44 & $9 \%$ & $1.45(0.3254)^{* *}$ \\
\hline Sublingual & 8 & $2.60 \%$ & 0 & $0.00 \%$ & 8 & $2 \%$ & $4.98(0.0255)^{*}$ \\
\hline \multicolumn{8}{|l|}{ Minor } \\
\hline Antrum & 46 & $14.94 \%$ & 2 & $1.06 \%$ & 48 & $10 \%$ & $25.85(<0.0001)^{*}$ \\
\hline Buccal Mucosa & 16 & $5.19 \%$ & 7 & $3.70 \%$ & 23 & $5 \%$ & $0.55(0.4564)^{* *}$ \\
\hline Cheek & 23 & $7.47 \%$ & 44 & $23.28 \%$ & 67 & $13 \%$ & $25.11(<0.0001)^{*}$ \\
\hline Gingiva & 2 & $0.65 \%$ & 2 & $1.06 \%$ & 4 & $1 \%$ & $0.24(0.6204)^{* *}$ \\
\hline Lower lip & 5 & $1.62 \%$ & 5 & $2.65 \%$ & 10 & $2 \%$ & $0.62(0.4308)^{* *}$ \\
\hline Mandible & 26 & $8.44 \%$ & 2 & $1.06 \%$ & 28 & $6 \%$ & $0.39(0.5320)^{* *}$ \\
\hline Maxilla & 7 & $2.27 \%$ & 1 & $0.53 \%$ & 8 & $2 \%$ & $2.24(0.1337)^{* *}$ \\
\hline Neck & 1 & $0.32 \%$ & 0 & $0.00 \%$ & 1 & $0 \%$ & $0.61(0.4329)^{* *}$ \\
\hline Orbito-zygomatic & 1 & $0.32 \%$ & 0 & $0.00 \%$ & 1 & $0 \%$ & $0.61(0.4329)^{* *}$ \\
\hline Palate & 94 & $30.52 \%$ & 47 & $24.87 \%$ & 141 & $28 \%$ & $1.73(0.1897)^{* *}$ \\
\hline $\begin{array}{l}\text { Preauricular } \\
\text { region }\end{array}$ & 1 & $0.32 \%$ & 0 & $0.00 \%$ & 1 & $0 \%$ & $0.61(0.4329)^{* *}$ \\
\hline Retromolar & 4 & $1.30 \%$ & 2 & $1.06 \%$ & 6 & $1 \%$ & $0.05(0.8116)^{* *}$ \\
\hline Tongue & 5 & $1.62 \%$ & 0 & $0.00 \%$ & 5 & $1 \%$ & $3.09(0.0783)^{* *}$ \\
\hline Upper lip & 3 & $0.97 \%$ & 6 & $3.17 \%$ & 9 & $2 \%$ & $3.18(0.0740)^{* *}$ \\
\hline NA & 2 & $0.65 \%$ & 10 & $5.29 \%$ & 12 & $2 \%$ & $10.71(0.0010)^{*}$ \\
\hline Total & 308 & $100.00 \%$ & 189 & $100.00 \%$ & 497 & $100 \%$ & \\
\hline
\end{tabular}

"Difference between both groups is statistically significant. ** Difference between both groups is not statistically significant.

\subsection{Data analysis}

Data from the selected 497 cases were collated and processed using the Epi-info software (Version 7.0, Atlanta, GA, USA). Categorical variables were analyzed as frequencies and percentages, while quantitative variables were summarized as means. Differences in mean were compared with Student's $t$ test and ANOVA while differences in proportion were compared with Chi-Square test. $p$-Values $<0.050$ were considered significant.

\section{3 | RESULTS}

\section{1 | Age distribution}

There was a statistically significant difference between the mean ages of patients with benign and malignant SGN $(p<0.001)$. The mean age of all patients with benign lesions was 37.1 with a range of 6-100 years, while the mean age of those with malignant lesions was 48.9 , with a range of 4-86 years. Of the benign SGN, data from UPTH had the highest mean age of 50.6 years while OAUTHC presented with the highest mean age of 53.6 for malignant lesions.

The peak age incidence of SGN in this study was bimodal between fourth and fifth decades, seen in 103 (20.7\%) cases (Table 1).
The highest frequency of 44 (23.2\%) for benign SGN was observed in the fourth decade while the highest frequency 64 (20.8\%) for malignant SGN was observed within the fifth decade and was statistically significant. Data from UCH and LUTH showed the highest frequency of malignant SGN, each with 86 cases, while the least was observed in LASUCOM with 17. UDUTH had the highest frequency of benign SGN (with 45 cases), while UPTH presented the least number (5) of benign SGN.

\subsection{Distribution of tumor diagnosis by gender}

There were 305 (62.0\%) females and 192 (38.0\%) males with a M:F of 1:1.6. Notably, in all the centers studied, both benign and malignant salivary gland tumors were more prevalent in females $(p<0.050)$. Both the commonest benign (pleomorphic adenoma) and the malignant (adenoid cystic carcinoma) lesions were most commonly seen in females. While this observation was statistically significant for adenocystic carcinoma $(p<0.050)$, it was not significant for pleomorphic adenoma (Table 2). Male predominance was found in patients with basal cell adenoma, carcinoma ex pleomorphic adenoma, and polymorphous low-grade adenocarcinoma. Equal gender distribution was, however, observed for mucoepidermoid carcinoma (MEC), salivary ductal carcinoma (SDC), and papillary cystadenocarcinoma (PCAC). 


\section{3 | Distribution of tumor diagnosis by site}

Most of the SGN originated from the minor salivary gland ( $n=351$, $70.6 \%$ ). The palate ( $n=141,28.0 \%$ ) was the commonest site for all SGN, followed by the parotid $(n=81,16.0 \%)$ and the cheek $(n=67$, $13.0 \%)$. Similarly, the palate was observed to have the highest number of both malignant $(n=94,30.5 \%)$ and benign $(n=47$, $24.9 \%)$ lesions; however, there was no statistical significant difference observed. Benign lesions of the cheek were statistically significantly more observed than malignant lesion from the same site (Table $3 ; p<0.001$ ). Antral lesions were mostly malignant ( $n=46 / 48, p<0.001$ ), as were all lesions from the sublingual gland ( $n=8 / 8, p$-value $=0.025$ ). In the major glands, malignant lesions ( $n=72 / 133,54.0 \%$ ) were found to be more than benign lesions (61/133, 46.0\%).

\subsection{Distribution of tumors by center}

The highest frequency of occurrence of SGN was observed in $\mathrm{UCH}$ ( $n=116,23.3 \%$ ), which was followed by LUTH ( $n=111,22.3 \%)$. The lowest frequency was seen in OAUTHC ( $n=34,6.8 \%)$. Of the total of 497 SGN seen over the study period, malignant SGN constituted 308 (62.0\%) while the benign lesion was 189 (38.0\%) (Table 4).

\section{5 | Regional distribution of SGN diagnosis by center}

Overall, of all recorded tumors per center, adenocystic carcinoma (ADCC) was found to have the highest frequency in LUTH (47), UCH (44), and OAUTHC (11), all in southwestern Nigeria. Among all benign lesions, pleomorphic adenoma (PA) was the most common in all centers, with highest frequencies in UDUTH (42) and UBTH (36).

\subsection{SGN distribution according to tumor diagnosis}

Overall, PA was the most frequent ( $n=164,33.0 \%$ ), closely followed by $\operatorname{ADCC}(n=142,28.6 \%)$ and MEC $(n=88,17.7 \%)$ (Table 5$)$. The

TAB LE 4 Distribution of tumor types in the different centers

\begin{tabular}{lccr} 
Location & Benign (\%) & Malignant $(\%)$ & \multicolumn{1}{l}{$\begin{array}{l}\text { Chi-squared test } \\
(p \text {-value) }\end{array}$} \\
UCH & $30(15.9 \%)$ & $86(27.9 \%)$ & $10.05(0.0015)^{\mathrm{a}}$ \\
LUTH & $25(13.2 \%)$ & $86(27.9 \%)$ & $14.17(0.0002)^{\mathrm{a}}$ \\
UDUTH & $46(24.3 \%)$ & $19(6.2 \%)$ & $33.10(<0.0001)^{\mathrm{a}}$ \\
OAUTHC & $13(6.9 \%)$ & $21(6.8 \%)$ & $0.01(0.9545)^{\mathrm{a}}$ \\
UPTH & $5(2.6 \%)$ & $33(10.7 \%)$ & $10.61(0.0011)^{\mathrm{a}}$ \\
UBTH & $39(20.6 \%)$ & $46(14.9 \%)$ & $2.86(0.0904)^{\mathrm{b}}$ \\
LASUCOM & $31(16.4 \%)$ & $17(5.5 \%)$ & $16.25(<0.0001)^{\mathrm{a}}$ \\
Total & $189(100.0 \%)$ & $308(100.0 \%)$ &
\end{tabular}

${ }^{a}$ Difference between the groups is statistically significant $(p<0.05)$.

${ }^{b}$ Difference between the groups is not statistically significant $(p>0.05)$. least common SGN was WT and oncocytoma both having a frequency of 1 each.

\section{4 | DISCUSSION}

Salivary gland tumors often pose diagnostic challenges (Peravali, Bhat, Upadya, Agarwal, \& Naag, 2015; Tyagi \& Dey, 2015), even in the most equipped centers in the world. This is more so in the African continent, where diagnostic resources are limited and need to be managed judiciously (Adeola, Soyele, Adefuye, Jimoh, \& Butali, 2017). To our knowledge, this is the largest multicenter study of SGN in Africa.

We observed mean ages of diagnosis for benign tumors to be 37.1 $( \pm 15.4)$ years and malignant tumors to be $48.9( \pm 17.3)$ years. The mean age of diagnosis for malignant tumors in our study is similar to that reported for both benign and malignant tumors in Tanzania (Masanja, Kalyanyama, \& Simon, 2003) and Brazil (Takahama Junior, Almeida, \& Kowalski, 2009). Our observed mean ages of diagnosis were, however, lower than ages reported in a study by SatkoStanko \& Longauerova, 2000 in Slovakia; where the mean ages reported for benign and malignant tumor were 46 and 53 years, respectively (Satko et al., 2000). Furthermore, the mean ages of diagnosis in our study are also lower than mean ages reported by Araya, Martinez, Niklander, Marshall, \& Esguep, 2015 in Chile (mean age for benign and malignant tumors were $53.3 \pm 19.09$ and $60.9 \pm 26.6$ ) (Araya et al., 2015), as well as ages reported by Tartaglione et al., 2015 in Italy (mean age for benign tumors, it was 50.7 years and malignant tumors was 65.2 years) (Tartaglione et al., 2015). The similarity in mean ages to the Tanzanian and Brazilian study could be due to the similar African genomic architecture in these populations which is different from the other populations.

TAB LE 5 Distribution of tumor diagnosis

\begin{tabular}{|lrr|}
\hline Diagnosis & Frequency $(\mathbf{n})$ & Percent $(\%)$ \\
\hline ADCC & 142 & $28.6 \%$ \\
\hline BCA & 19 & $3.8 \%$ \\
\hline Ca-Ex PA & 21 & $4.2 \%$ \\
\hline Malignant myoepithelioma & 7 & $1.4 \%$ \\
\hline MEC & 88 & $17.7 \%$ \\
\hline Mucinous Carcinoma & 2 & $0.4 \%$ \\
\hline Oncocytoma & 1 & $0.2 \%$ \\
\hline PA & 164 & $33.0 \%$ \\
\hline PCAC & 4 & $0.8 \%$ \\
\hline PLGA & 42 & $8.5 \%$ \\
\hline SDC & 6 & $1.2 \%$ \\
\hline WT & 1 & $0.2 \%$ \\
\hline TOTAL & 497 & $100.0 \%$ \\
\hline
\end{tabular}

Note. ADCC, Adenoid cystic carcinoma; BCA, Basal cell adenoma; CAexPA, carcinoma ex pleomorphic adenoma; MEC, Mucoepidermoid carcinoma; PA, Pleomorphic adenoma; PCAC, Papillary Cystadenocarcinoma; PLGA, Polymorphous low-grade adenocarcinoma; SDC, Salivary ductal carcinoma; WT, Warthin tumor. 
Similar age trends were observed for benign and malignant SGN with peak incidences at 44 and 59 years, respectively. The higher incidence and age in the malignant group is consistent with what has been reported in most studies (Araya et al., 2015; Masanja et al., 2003; Satko et al., 2000; Takahama Junior et al., 2009; Tartaglione et al., 2015).

However, the decline in number of benign and malignant cases after ages 30-39 and 40-49 years of age, respectively, may reflect an increase in mortality or comorbidity in subsequent ages, limiting the number of new cases recorded at the hospital.

The histopathological pattern of salivary gland tumors has been reported by several authors from different geopolitical zones in Nigeria, showing diverse distribution patterns (Fomete et al., 2015; Jude \& Olu-Eddo, 2014; Ladeinde et al., 2007; Otoh et al., 2005). This study found more malignant salivary gland tumors than benign tumors which are similar to reports by Fomete et al (2015), and Aliyu et al. (2016) but is in contrast to the report by Shishegar et al (2011) and Jude and Olu-Eddo (2014), who found more benign salivary gland tumors. These variations in benign and malignant SGN incidence may reflect regional differences and highlight the need for multicenter collaborations to get a truly representative disease burden. As reported by several studies (Bobati, Patil, \& Dombale, 2017; Otoh et al., 2005; Sando, Fokouo, Mebada, Djomou, \& A ND and Oyono JL, 2016; Shishegar et al., 2011), pleomorphic adenoma was the most common salivary gland tumor overall and the most common benign tumor, similar to the findings from our study. In a study in north central Nigeria (Fomete et al., 2015), in general, ADCC was reported as the most common salivary gland tumor; albeit second overall in our study. Sando et al (2016) in Cameroon, Bobati et al (2017) in India and Lima et al (2005) in Brazil found ADCC as the most common malignant salivary gland tumor in their case series. Among the malignant tumors, however, some authors (including Nigerians) have reported mucoepidermoid carcinoma, as the most frequent tumor (Pinkston \& Cole, 1999; Sun, Curtis, Melbye, \& Goedert, 1999). These findings show a variation in the prevalence of the histological types which may be attributed to the type of predisposing etiological factors in the different geographic zones. Further studies on these regional predisposing factors may elicit the reasons for the variation in histopathological patterns of presentation.

This study also showed a wide anatomic distribution of SGN, including difference between centers investigated. Neoplasms of minor salivary glands were more common than those from major salivary glands. This is similar to the study of Ladeinde et al. (2007) but differs from several other studies which reported more neoplasms of the major than the minor glands (Ito, Ito, Vargas, Almeida, \& Lopes, 2005; Lawal, Adisa, Kolude, Adeyemi, \& Olajide, 2013; Otoh et al., 2005). The palate was the most commonly affected site followed by the parotid gland in our study. This contrasts with many studies that observed the parotid gland as the most commonly affected primary site (Ito et al., 2005; Tian et al., 2010). The reason for this discrepancy is not clear, but it suffices to know that the pattern may be related to data available to the researchers.
The highest prevalence in ADCC was seen in LUTH and $\mathrm{UCH}$ in the southwest zone. This finding is consistent with report from a previous single-center study by Ladeinde et al (2007) and Lawal et al (2013), respectively, who in their studies observed ADCC as the most common malignant salivary gland tumors in their centers. The low frequency of ADCC in UPTH, south-south in comparison with LUTH and UCH may be due to the low number of cases seen there, and the fact that LUTH and UCH are older, and more well-established centers. However, UPTH and UDUTH observed a high frequency of MEC which concurs with reports by Sun et al (1999) and Pinkston and Cole (Pinkston \& Cole, 1999). This alludes to the variation in the occurrence of salivary gland tumors in the different geopolitical zones (Sando et al., 2016). The single most common lesion (benign and malignant) in this study is the pleomorphic adenoma, and this is similar to the observation of Ladeinde et al (2007), Oti, Donkor, Obiri-Yeboah, and Afriyie-Owusu (2013), Bahra, Butt, Dimba, and Macigo (2012) but contrasts the observations of Aliyu et al. (2016) and Omitola, lyogun, and Osagbemiro (2016), in which squamous cell carcinoma and mucoepidermoid carcinoma were the most common lesions, respectively. Similar to the observation of Ladeinde et al. (2007), Oti et al. (2013), and Bahra et al. (2012), adenocytic carcinoma was the most common malignant lesion in this study.

Among the benign lesions, PA was the most prevalent tumor in our study, which is similar to earlier reports (Bobati et al., 2017; Otoh et al., 2005; Sando et al., 2016; Shishegar et al., 2011). The highest occurrence of PA was seen in UDUTH, which is in northwestern Nigeria, followed by UBTH Benin, which is in the south-south geopolitical zone. A previous study in UDUTH by Aliyu et al. (2016) reported more malignant tumors. Warthins tumor and oncocytoma were of a low prevalence in this study which agrees with findings from previous studies on the low frequency of occurrence of these tumors (Aliyu et al., 2016; Fomete et al., 2015; Sando et al., 2016). As found in other studies (Bahra et al., 2012; Jones, Craig, Speight, \& Franklin, 2008; Omitola et al., 2016), salivary gland lesions affected more females than males. This may be related to the general belief that females tend to seek health care more than males (Hunt, Adamson, Hewitt, \& Nazareth, 2011); although male preponderance of SGNs has been reported as well (Ladeinde et al., 2007; Oti et al., 2013).

The prevalence of pleomorphic adenoma which is the commonest benign lesion and the commonest lesion overall in this study was significantly higher in females while carcinoma ex pleomorphic adenoma was significantly higher in males. The reason for this observation is not clear, but other studies have reported both similar (Aliyu et al., 2016; Bahra et al., 2012) and contrary findings (Oti et al., 2013). Ladeinde et al. (2007) reported equal prevalence in both sexes for ca ex pleomorphic adenoma. Variations in the incidences of carcinoma ex pleomorphic adenoma may be a reflection of the total number of cases accessible from individual centers, and warrants further research. Adenoid cystic carcinoma which is the most common malignant lesion in this study was also most prevalence in females. This observation is similar to the observation of Ladeinde et al (2007), but contrary to the reports of most other researchers that have reported the prevalence of this lesion in males (Aliyu et al., 2016; Bahra et al., 2012; Oti et al., 2013). 


\section{5 | CONCLUSION}

We present in this study, the largest multicenter evaluation of SGN on the African continent. Even though, up to $80 \%$ of the global cancer burden can be found in low- and middle-income countries (LMICs), it receives only $5 \%$ of the global cancer spending (Knaul, Atun, Farmer, \& Frenk, 2013). As African oral pathologists, we recognize the importance of academic partnership and multicenter initiatives to improve our understanding of oral diseases within the African continent. Using this multicenter approach effectively, we previously investigated the burden of oral cancer in southern and western Nigeria (Omitola et al., 2017). We have evaluated the clinic-pathological characteristics of close to 500 salivary gland lesions across seven tertiary centers in northern and southern Nigeria. Overall, we found pleomorphic adenoma to be the most common SGN. This was also true in the benign category. Adenocystic carcinoma was found to be the commonest malignant salivary gland neoplasm. Cystadenocarcinomas and oncocytomas were the least frequent in our study. Findings in this collaborative team research will help oral pathologists to understand areas in salivary gland neoplasia that require urgent research efforts on the African continent. Also, an equitable distribution of manpower, increased education and awareness of this salivary gland lesion in all the regions of Nigeria, will serve to promote early detection. This study also provides a foundation for further studies on etiology and prevention.

\section{ACKNOWLEDGEMENTS}

HAA would like to thank the South African Medical Research Council (SAMRC) for a midcareer scientist research fellowship. AB is a recipient of a NIDCR K99/R00 and Robert Wood Johnson Foundation Grant. The funders played no role in the design or interpretation of the manuscript or the decision to publish.

\section{CONFLICT OF INTEREST}

None to declare.

\section{AUTHOR CONTRIBUTIONS}

OGO, OOS AB, and HAA conceptualized, designed, prepared, and critically revised the manuscript, tables, and figure. $A O A, D O, O A E$, $\mathrm{KEA}, \mathrm{AOA}, \mathrm{OO}, \mathrm{AML}, \mathrm{OS}, \mathrm{ROB}$, and $\mathrm{AOL}$ were involved in the design, and critical intellectual revision of the manuscript. All authors were involved in preparing the manuscript and had final approval of the submitted and published versions.

\section{ORCID}

Henry Ademola Adeola (iD http://orcid.org/0000-0003-2896-0583

\section{REFERENCES}

Adeola, H. A., Soyele, O. O., Adefuye, A. O., Jimoh, S. A., \& Butali, A. (2017). Omics-based molecular techniques in oral pathology centred cancer: Prospect and challenges in Africa. Cancer Cell International, $17,61$.

Aliyu, D., Iseh, K. R., Sahabi, S. M., Amutta, S. M., Abdullahi, M., \& Inoh, M. I. (2016). Pattern of Salivary Gland Tumour in Sokoto, North-Western Nigeria. International Journal of Clinical Medicine, 7, 347-352.

Araya, J., Martinez, R., Niklander, S., Marshall, M., \& Esguep, A. (2015). Incidence and prevalence of salivary gland tumours in Valparaiso, Chile. Medicina Oral, Patologia Oral Y Cirugia Bucal, 20, e532-e539.

Arshad, A. R. (1998). Parotid swellings: Report of 110 consecutive cases. The Medical Journal of Malaysia, 53, 417-422.

Bahra, J., Butt, F., Dimba, E., \& Macigo, F. (2012). Patterns of salivary tumours at a university teaching hospital in Kenya. Open Journal of Stomatology, 2, 280-285.

Barnes, L. (2009). Surgical pathology of the head and neck. New York, NY: Marcel Dekker Inc.

Bobati, S. S., Patil, B. V., \& Dombale, V. D. (2017). Histopathological study of salivary gland tumors. Journal of Oral and Maxillofacial Pathology, 21, 46-50. https://doi.org/10.4103/0973-029x.203762

Boukheris, H., Curtis, R. E., Land, C. E., \& Dores, G. M. (2009). Incidence of carcinoma of the major salivary glands according to the WHO classification, 1992 to 2006: A population-based study in the United States. Cancer Epidemiology, Biomarkers \& Prevention, 18, 2899-2906.

Chaudhry, A. P., Cutler, L. S., Leifer, C., Labay, G., Satchidanand, S., \& Yamane, G. M. (1989). Ultrastructural-study of the histogenesis of salivary-gland mucoepidermoid carcinoma. Journal of Oral Pathology \& Medicine, 18, 400-409.

de Oliveira, F. A., Duarte, E. C., Taveira, C. T., Maximo, A. A., de Aquino, E. C., Alencar Rde, C., \& Vencio, E. F. (2009). Salivary gland tumor: A review of 599 cases in a Brazilian population. Head and Neck Pathology, 3, 271-275. https://doi.org/10.1007/ s12105-009-0139-9

Ebrahim, S., Singh, B., \& Ramklass, S. S. (2014). HIV-associated salivary gland enlargement: A clinical review. SADJ: Journal of the South African Dental Association, 69, 400-403.

El-Naggar, A., Chan, J. K. C., Grandis, J. R., Takata, T., \& Slootweg, P. J. (2017). WHO Classification of head and neck tumours. Lyon, France: International Agency for Research on Cancer.

Eveson, J. W., \& Cawson, R. A. (1985). Salivary gland tumours. A review of 2410 cases with particular reference to histological types, site, age and sex distribution. The Journal of Pathology, 146, 51-58.

Fomete, B., Adebayo, E. T., \& Ononiwu, C. N. (2015). Management of salivary gland tumors in a Nigerian tertiary institution. Annals of African Medicine, 14, 148-154. https://doi.org/10.4103/1596-3519.152071

Fragkioudaki, S., Mavragani, C. P., \& Moutsopoulos, H. M. (2016). Predicting the risk for lymphoma development in Sjogren syndrome: An easy tool for clinical use. Medicine, 95, e3766.

Freling, N., Crippa, F., \& Maroldi, R. (2016). Staging and follow-up of high-grade malignant salivary gland tumours: The role of traditional versus functional imaging approaches - A review. Oral Oncology, 60 157-166.

Haldar, S., Sinnott, J. D., Tekeli, K. M., Turner, S. S., \& Howlett, D. C. (2016). Biopsy of parotid masses: Review of current techniques. World Journal of Radiology, 8, 501-505. https://doi.org/10.4329/wjr.v8.i5.501

Hunt, K., Adamson, J., Hewitt, C., \& Nazareth, I. (2011). Do women consult more than men? A review of gender and consultation for back pain and headache. Journal of Health Services Research \& Policy, 16, 108-117. https://doi.org/10.1258/jhsrp.2010.009131

Ito, F. A., Ito, K., Vargas, P. A., de Almeida, O. P., \& Lopes, M. A. (2005). Salivary gland tumors in a Brazilian population: A retrospective study 
of 496 cases. International Journal of Oral and Maxillofacial Surgery, 34 533-536. https://doi.org/10.1016/j.ijom.2005.02.005

Jones, A. V., Craig, G. T., Speight, P. M., \& Franklin, C. D. (2008). The range and demographics of salivary gland tumours diagnosed in a UK population. Oral Oncology, 44, 407-417.

Jude, U., \& Olu-Eddo, A. N. (2014). Salivary gland tumors, a twenty-year retrospective study. African Journal of Medical and Health Sciences, 13, 24-29. https://doi.org/10.4103/2384-5589.139439

Knaul, F. M., Atun, R., Farmer, P., \& Frenk, J. (2013). Seizing the opportunity to close the cancer divide. Lancet, 381, 2238-2239.

Ladeinde, A. L., Adeyemo, W. L., Ogunlewe, M. O., Ajayi, O. F., \& Omitola, O. G. (2007). Salivary gland tumours: A 15-year review at the Dental Centre Lagos University Teaching Hospital. African Journal of Medicine and Medical Sciences, 36, 299-304.

Lawal, A. O., Adisa, A. O., Kolude, B., Adeyemi, B. F., \& Olajide, M. A. (2013). A review of 413 salivary gland tumours in the head and neck region. Journal of Clinical and Experimental Dentistry, 5, e218-e222.

Leivo, I. (2006). Insights into a complex group of neoplastic disease: Advances in histopathologic classification and molecular pathology of salivary gland cancer. Acta Oncologica, 45, 662-668.

Li, T., Chiang, M. T., Chiu, K. C., Lai, C. H., Liu, S. Y., \& Shieh, Y. S. (2017). The association of betel quid, alcohol, and cigarettes with salivary gland tumor-A case-control study. Journal of Dental Sciences, 12, 151-155. https://doi.org/10.1016/j.jds.2016.12.002

Li, L. J., Li, Y., Wen, Y. M., Liu, H., \& Zhao, H. W. (2008). Clinical analysis of salivary gland tumor cases in West China in past 50 years. Oral Oncology, 44, 187-192.

Lima, S. S., Soares, A. F., de Amorim, R. F., \& Freitas Rde, A. (2005). Epidemiologic profile of salivary gland neoplasms: Analysis of 245 cases. Brazilian Journal of Otorhinolaryngology, 71, 335-340.

Loyola, A. M., de Araujo, V. C., de Sousa, S. O., \& de Araujo, N. S. (1995). Minor salivary gland tumours. A retrospective study of 164 cases in a Brazilian population. European Journal of Cancer. Part B, Oral Oncology, 31B, 197-201.

Marx, R., \& Stern, D. (2003). Oral and maxillofacial pathology. Chicago, IL: Quintessence.

Masanja, M. I., Kalyanyama, B. M., \& Simon, E. N. (2003). Salivary gland tumours in Tanzania. East African Medical Journal, 80, 429-434.

Mehanna, H., McQueen, A., Robinson, M., \& Paleri, V. (2012). Salivary gland swellings. BMJ, 345, e6794.

Omitola, O., Iyogun, C. A., \& Osagbemiro, B. O. (2016). Salivary gland tumours in South-South Nigerian Teaching Hospital. Afr J of Oral and Maxillofac Path. Med, 2, 17-21.

Omitola, O. G., Soyele, O. O., Sigbeku, O., Okoh, D., Akinshipo, A. O., Butali, A., \& Adeola, H. A. (2017). A multi-centre evaluation of oral cancer in Southern and Western Nigeria: An African oral pathology research consortium initiative. Pan African Medical Journal, 28, 000000. https://doi.org/10.11604/pamj.2017.28.64.13089

Oti, A., Donkor, P., Obiri-Yeboah, S., \& Afriyie-Owusu, O. (2013). Salivary Gland Tumours at Komfo Anokye Teaching Hospital, Ghana. Surgical Science, 4, 135-139.

Otoh, E. C., Johnson, N. W., Olasoji, H., Danfillo, I. S., \& Adeleke, O. A. (2005). Salivary gland neoplasms in Maiduguri, north-eastern Nigeria. Oral Diseases, 11, 386-391.

Peravali, R. K., Bhat, H. H., Upadya, V. H., Agarwal, A., \& Naag, S. (2015). Salivary gland tumors: A diagnostic dilemma!. Journal of Maxillofacial and Oral Surgery, 14, 438-442. https://doi.org/10.1007/ s12663-014-0665-1

Pinkston, J. A., \& Cole, P. (1999). Incidence rates of salivary gland tumors: Results from a population-based study. Otolaryngology-head and Neck Surgery, 120, 834-840.

Preston-Martin, S., \& White, S. C. (1990). Brain and salivary gland tumors related to prior dental radiography: Implications for current practice. Journal of the American Dental Association, 120, 151-158.
Ribeiro Kde, C., Kowalski, L. P., Saba, L. M., \& de Camargo, B. (2002). Epithelial salivary glands neoplasms in children and adolescents: A forty-four-year experience. Medical and Pediatric Oncology, 39, 594-600.

Rudack, C., Jörg, S., Kloska, S., Stoll, W., \& Thiede, O. (2007). Neither MRI, CT nor US is superior to diagnose tumors in the salivary glandsan extended case study. Head \& Face Medicine, 3, 19.

Sando, Z., Fokouo, J. V., Mebada, A. O., Djomou, F., \& A ND and Oyono $\mathrm{JL}, \quad$ (2016). Epidemiological and histopathological patterns of salivary gland tumors in Cameroon. Pan African Medical Journal, $23,66$.

Satko, I., Stanko, P., \& Longauerova, I. (2000). Salivary gland tumours treated in the stomatological clinics in Bratislava. Journal of CranioMaxillo-Facial Surgery, 28, 56-61.

Shishegar, M., Ashraf, M. J., Azarpira, N., Khademi, B., Hashemi, B., \& Ashrafi, A. (2011). Salivary gland tumors in maxillofacial region: A retrospective study of 130 cases in a southern Iranian population. Pathology Research International, 2011, 934350. https://doi. org/10.4061/2011/934350

Sood, S., McGurk, M., \& Vaz, F. (2016). Management of Salivary Gland Tumours: United Kingdom National Multidisciplinary Guidelines. Journal of Laryngology and Otology, 130, S142-S149.

Speight, P. M., \& Barrett, A. W. (2002). Salivary gland tumours. Oral Diseases, 8, 229-240.

Sun, E. C., Curtis, R., Melbye, M., \& Goedert, J. J. (1999). Salivary gland cancer in the United States. Cancer Epidemiology, Biomarkers \& Prevention, 8, 1095-1100.

Takahama Junior, A., Almeida, O. P., \& Kowalski, L. P. (2009). Parotid neoplasms: Analysis of 600 patients attended at a single institution. Brazilian Journal of Otorhinolaryngology, 75, 497-501.

Tartaglione, T., Botto, A., Sciandra, M., Gaudino, S., Danieli, L., Parrilla, C., ... Colosimo, C. (2015). Differential diagnosis of parotid gland tumours: Which magnetic resonance findings should be taken in account? Acta Otorhinolaryngologica Italica, 35, 314-320.

Thoeny, H. C. (2007). Imaging of salivary gland tumours. Cancer Imaging, 7, 52-62.

Tian, Z., Li, L., Wang, L., Hu, Y., \& Li, J. (2010). Salivary gland neoplasms in oral and maxillofacial regions: A 23-year retrospective study of 6982 cases in an eastern Chinese population. International Journal of Oral and Maxillofacial Surgery, 39, 235-242.

Tyagi, R., \& Dey, P. (2015). Diagnostic problems of salivary gland tumors. Diagnostic Cytopathology, 43, 495-509.

Valstar, M. H., de Ridder, M., van den Broek, E. C., Stuiver, M. M., van Dijk, B. A. C., van Velthuysen, M. L. F., ... Smeele, L. E. (2017). Salivary gland pleomorphic adenoma in the Netherlands: A nationwide observational study of primary tumor incidence, malignant transformation, recurrence, and risk factors for recurrence. Oral Oncology, 66, 93-99.

Yaor, M. A. (2010). The pattern of presentation of salivary gland tumors in Africa: A review of published reports. Ear, Nose, and Throat Journal, 89, E17-E21.

Yin, L. X., \& Ha, P. K. (2016). Genetic alterations in salivary gland cancers. Cancer, 122, 1822-1831.

How to cite this article: Omitola OG, Soyele OO, Butali A, et al. Descriptive epidemiology of salivary gland neoplasms in Nigeria: An AOPRC multicenter tertiary hospital study. Oral Dis. 2019;25:142-149. https://doi.org/10.1111/odi.12956 